
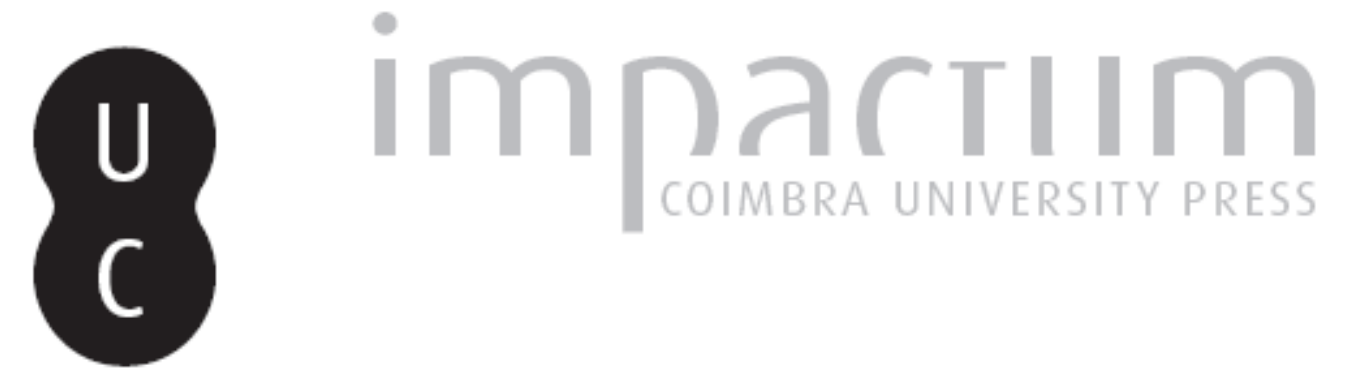

\title{
Páginas de Suetónio: a morte anunciada de Domiciano
}

Autor(es): Brandão, José Luís

Publicado por: Imprensa da Universidade de Coimbra

URL persistente:

URI:http://hdl.handle.net/10316.2/34005

DOI:

DOI:http://dx.doi.org/10.14195/0872-2110_58_9

Accessed : $\quad$ 26-Apr-2023 12:16:46

A navegação consulta e descarregamento dos títulos inseridos nas Bibliotecas Digitais UC Digitalis, UC Pombalina e UC Impactum, pressupõem a aceitação plena e sem reservas dos Termos e Condições de Uso destas Bibliotecas Digitais, disponíveis em https://digitalis.uc.pt/pt-pt/termos.

Conforme exposto nos referidos Termos e Condições de Uso, o descarregamento de títulos de acesso restrito requer uma licença válida de autorização devendo o utilizador aceder ao(s) documento(s) a partir de um endereço de IP da instituição detentora da supramencionada licença.

Ao utilizador é apenas permitido o descarregamento para uso pessoal, pelo que o emprego do(s) título(s) descarregado(s) para outro fim, designadamente comercial, carece de autorização do respetivo autor ou editor da obra.

Na medida em que todas as obras da UC Digitalis se encontram protegidas pelo Código do Direito de Autor e Direitos Conexos e demais legislação aplicável, toda a cópia, parcial ou total, deste documento, nos casos em que é legalmente admitida, deverá conter ou fazer-se acompanhar por este aviso.

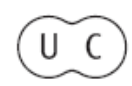


COIMBRA • 2013
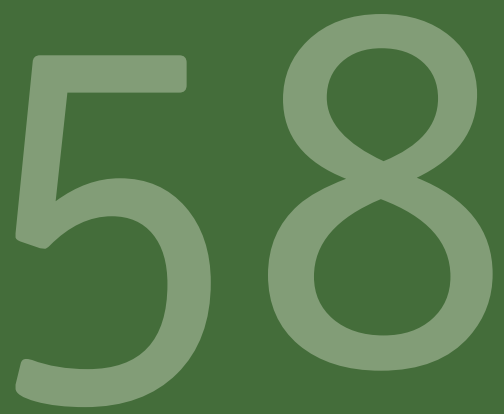

BOLETIM DE

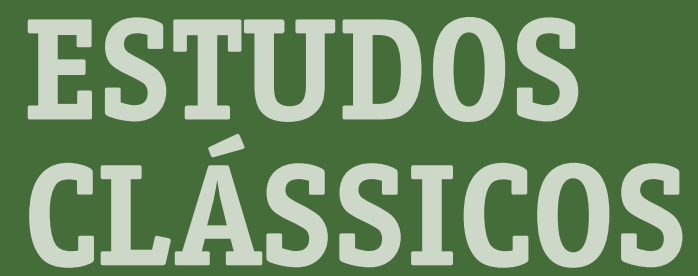

\author{
ASSOCIAÇÃO \\ PORTUGUESA \\ DE ESTUDOS \\ CLÁSSICOS \\ INSTITUTO \\ DE ESTUDOS \\ CLÁSSICOS
}




\section{Páginas de Suetónio: \\ a morte anunciada de Domiciano}

JOSÉ LUÍS BRANDÃO

Na sequência dos relatos de magnicídios transmitidos por Suetónio, anteriormente analisados no Boletim de Estudos Clássicos, pomos desta vez à consideração a narrativa da morte de Domiciano. Com a biografia deste imperador Suetónio encerra as suas Vidas dos Césares. Domiciano é também o último imperador da dinastia dos Flávios, família de origem equestre que subiu ao poder em 69 d.C. na sequência dos conflitos militares que, depois da morte de Nero (em Junho de 68), fizeram desfilar no Palatino quatro imperadores: Galba, Otão, Vitélio e, finalmente, Vespasiano ${ }^{1}$. A Vespasiano (imperador de 69 a 79), sucederam os filhos: Tito, que morreu de doença em 81, e Domiciano, assassinado em 96. A esta família fica a dever-se, por exemplo, o Anfiteatro Flávio, conhecido como Coliseu (devido à proximidade com o colosso de Nero, transformado em estátua do sol), e, no que nos diz mais respeito, a promoção, por parte de Vespasiano, das comunidades hispânicas, através da concessão da cidadania romana aos magistrados locais e do direito latino (ius Latii) aos restantes habitantes.

\section{Contexto}

A Vida de Domiciano contrasta desde o início com a do irmão, Tito. A imagem inicial é a oposta, e a evolução psicológica e moral é a inversa.

1 Brandão, J. L. (2010), "Páginas de Suetónio: a morte de Galba", Boletim de Estudos Clássicos 53 39-46. 
Começa por ser apresentado com contornos negativos, passa por um período positivo, depois da ascensão ao poder, para se tornar gradualmente um tirano cruel e rapace. Depois da acme que se atingira em Tito, segue-se o já esperado momento descendente. Suetónio usa as técnicas habituais para acentuar o bom nos bons e o mau nos tiranos. Se em Vespasiano e Tito são escamoteados alguns elementos que poderiam enegrecer a imagem positiva destes imperadores, em Domiciano a tónica nos aspectos negativos e a organização da biografia contribuem para sublinhar a imagem de um tirano, cuja crueldade e misantropia vão aumentando com o tempo. 0 carácter eminentemente positivo das Vidas de Vespasiano e Tito contribui para acentuar, pelo contraste, o negrume da Vida do último dos Flávios. Pelos actos que envolvem a ascensão de Domiciano ao império o texto de Suetónio parece querer aproximar este principado de uma usurpação. Desde as insídias contra o irmão até ao último sopro de vida, passando pela execução de Métio Pompusiano, que se dizia ter um horóscopo anunciador do império, e dos astrólogos que anunciavam o fim de Domiciano, toda esta Vida é uma luta vã contra um destino adverso. Mas a morte é apresentada também como o castigo merecido pela actuação: a progressão até um estádio intolerável de crueldade, rapacidade e arrogância, numa gradação conseguida, como habitualmente, à custa de alguma deformação histórica.

O assassínio aparece, como se disse, aos olhos do biógrafo como uma consequência da sua conduta despótica (Dom. 14.1): Per haec terribilis cunctis et inuisus, tandem oppressus est <...> amicorum libertorumque intimorum simul et uxoris ( CCom tais atitudes, tornou-se objecto de terror e de ódio para todos e acabou por ser morto numa conjugação de esforços dos amigos e libertos mais chegados e até da mulher»). O nexo de causalidade entre a tirania e a morte violenta é semelhante ao estabelecido para morte de outros imperadores, como Júlio César ${ }^{2}$, Calígula $^{3}$ ou Nero ${ }^{4}$. Trata-se,

2 Suet. Jul. 76.1. Vide Brandão, J. L. (2011), “Páginas de Suetónio: a morte de César”, Boletim de Estudos Clássicos 55 31-37.

3 Suet. Cal. 56.1.

4 Nero 40.1. Vide Brandão, J. L. (2008), “Páginas de Suetónio: o último dia do artifex 
como se percebe, de uma conjura palaciana que envolve mesmo a imperatriz Domícia Longina, como sugerem também Díon Cássio (67.15.1-4) e Aurélio Victor (11.7; e seu Epitomator 11.11). Díon Cássio (67.15.4) fala da entrega aos conjurados, por parte de Domícia, de uma lista de suspeitos de Domiciano, na qual ela própria estaria incluída. Domiciano é retratado segundo os lugares-comuns do tirano universalmente odiado e desconfiado em relação a todos os que o rodeiam, com ecos da caracterização de Tibério, refugiado na segurança do rochedo de Cápreas 5 .

Mas o medo de Domiciano tem ainda outra explicação. Fundamentando-se na superstição do imperador e na sua obsessão pela astrologia - e segundo Díon Cássio (67.15.6), Domiciano escrutinava até a data de nascimento dos possíveis rivais -, Suetónio afirma que annum diemque ultimum uitae iam pridem suspectum habebat, horam etiam nec non et genus mortis ("Já muito antes suspeitava qual seria o ano e o dia e até a hora e não menos o tipo de morte»). A fonte de tal conhecimento seriam os astrólogos (os Caldeus), mas também afirmações do próprio Vespasiano que, em determinada altura, ao ver o filho abster-se de cogumelos, o aconselhara a ter antes cuidado com o ferro. Embora desaprove a cedência dos imperadores à astrologia em prejuízo da religião tradicional, Suetónio mostra-se crente neste tipo de previsões, e em especial nos sonhos, como atesta Plínio (Ep. 1.18.1). Pelo que dá crédito à suspeita de Domiciano e atribui estatuto de presságio ao conselho trocista de Vespasiano - que bem poderia ter sido uma das graçolas características da bonacheirice deste imperador. De resto, o biógrafo já antes conferira a Vespasiano autoridade em termos de conhecimento do futuro dos seus, quando dissera que, através da astrologia, sabia que só os filhos lhe sucederiam. Acrescentara ainda um sonho daquele imperador, em que via no seu átrio uma balança que, num dos pratos, continha Cláudio e Nero e, no outro, Vespasiano e os filhos, sinal de que os três Flávios governariam

Nero", Boletim de Estudos Clássicos 49 49-59.

5 Suet. Tib. 63.1: Quam inter haec non modo inuisus ac detestabilis, sed praetrepidus quoque atque etiam contumeliis obnoxius uixerit, multa indicia sunt. 
por um período igual ao daqueles dois Júlio-Cláudios (Ves. 25). Assim, o fim da dinastia estava marcado pela previsão do seu fundador.

Portanto, neste relato de morte, a consciência do aproximar da hora fatal é um motivo fundamental e fonte de terror: tempore uero suspecti periculi appropinquante sollicitior in dies porticuum, in quibus spatiari consuerat, parietes phengite lapide distinxit, e cuius splendore per imagines quidquid a tergo fieret prouideret (Dom.14.4) («Mais inquieto de dia para dia, à medida que se aproximava a data do suspeitado perigo, ornou as paredes dos pórticos, pelos quais costumava passear, com placas de fengite, que lhe permitiam ver o que se passava atrás das costas»). O medo e o tempo evoluem na proporção inversa. Cada vez mais temeroso, interrogava os prisioneiros a sós, em lugar secreto e segurando nas mãos as cadeias e, para desincentivar atentados da parte dos seus serviçais, condenou Epafrodito, que ajudara Nero a suicidar-se (Nero 49.3), para desencorajar tal exemplo.

o crime que, segundo o biógrafo, contribuiu para apressar o atentado foi a morte intempestiva e mal fundamentada de Flávio Clemente, primo do imperador, e cônsul ordinário de 95 (Dom. 15.1). A acusação de inertia, referida por Suetónio, combinada com a de ateísmo, atestada por Díon Cássio (67.14.1), e que era aplicada também a muitos convertidos ao judaísmo, fizeram alguns colocarem a hipótese de se tratar de um cristão ou judeu prosélito ${ }^{6}$. Para salientar a conexão desta morte com o assassinato de Domiciano, Suetónio refere imediatamente uma série de presságios, um oráculo negativo da Fortuna de Preneste e um sonho do próprio imperador em que Minerva, deusa da sua especial veneração, lhe retira a protecção. E, no cume da gradação, figura a arrepiante história do Astrólogo, Ascletarião que, tal como predissera, é devorado pelos cães, quando a sua pira é derrubada por uma tempestade, apesar de Domiciano tentar contrariar tal destino para o desacreditar (Dom.15.2-3). O biógrafo centra-se então nos acontecimentos a partir da véspera do assassínio com uma narrativa mais factual, que aqui se transcreve a seguir.

6 Díon acrescenta que a esposa, Flávia Domitila, sobrinha do imperador, foi exilada na ilha de Pandatária. 


\section{0 texto (Dom. 16-17)}

Pridie quam periret, cum oblatos tubures seruari iussisset in crastinum, adiecit: 'si modo uti licuerit,' et conuersus ad proximos affirmauit fore ut sequenti die luna se in aquario cruentaret factumque aliquod existeret, de quo loquerentur homines per terrarum orbem. At circa mediam noctem ita est exterritus, ut e strato prosiliret. Dehinc mane haruspicem ex Germania missum, qui consultus de fulgure mutationem rerum praedixerat, audiit condemnauitque. Ac dum exulceratam in fronte uerrucam uehementius scalpit, profluente sanguine: 'utinam,' inquit, 'hactenus.' tunc horas requirenti pro quinta, quam metuebat, sexta ex industria nuntiata est. His uelut transacto iam periculo laetum festinantemque ad corporis curam Parthenius cubiculo praepositus conuertit, nuntians esse qui magnum nescio quid afferret, nec differendum. Itaque summotis omnibus in cubiculum se recepit atque ibi occisus est.

De insidiarum caedisque genere haec fere diuulgata sunt. Cunctantibus conspiratis, quando et quo modo, id est lauantemne an cenantem adgrederentur, Stephanus, Domitillae procurator et tunc interceptarum pecuniarum reus, consilium operamque obtulit. Ac sinisteriore brachio uelut aegro lanis fasciisque per aliquot dies ad auertendam suspicionem obuoluto, sub ipsam horam dolonem interiecit; professusque conspirationis indicium et ob hoc admissus legenti traditum a se libellum et attonito suffodit inguina. Saucium ac repugnantem adorti Clodianus cornicularius et Maximus Partheni libertus et Satur decurio cubiculariorum et quidam e gladiatorio ludo uulneribus septem contrucidarunt. Puer, qui curae Larum cubiculi ex consuetu dine assistens interfuit caedi, hoc amplius narrabat, iussum se a Domitiano ad primum statim uulnus pugionem puluino subditum porrigere ac ministros uocare, neque ad caput quidquam excepto capulo et praeterea clausa omnia repperisse; atque illum ínterim arrepto deductoque ad terram Stephano conluctatum diu, dum modo ferrum extorquere, modo quanquam laniatis digitis oculos effodere conatur.

Occisus est XIIII. Kal. Octb. anno aetatis quadragensimo quinto, imperii 
quinto decimo. cadauer eius populari sandapila per uispillones exportatum Phyllis nutrix in suburbano suo Latina uia funerauit, sed reliquias templo Flauiae gentis clam intulit cineribusque Iuliae Titi filiae, quam et ipsam educarat, conmiscuit.

\section{TRADUÇÃO}

«Na véspera de morrer, ao mandar guardar para o dia seguinte umas túberas que lhe tinham oferecido, acrescentou "se ao menos me for permitido saboreá-las!» e, voltando-se para os íntimos, asseverou que no dia seguinte a lua iria cobrir-se de sangue no signo de aquário e ocorreria algo de que todos os homens falariam por todo o mundo. E por volta da meia noite, foi acometido de tal terror, que saltou do leito.

Na manhã seguinte, ouviu e condenou à morte um arúspice enviado da Germânia, que, consultado acerca de um relâmpago, tinha vaticinado uma mudança no poder. E, ao arranhar com força uma verruga inflamada na fronte até fazer sangue, disse: «Oxalá seja quanto baste!». Então, quando perguntou as horas, disseram-lhe propositadamente que era a sexta, em vez da quinta que ele temia. Satisfeito com tal resposta, julgando o perigo passado, tratava de ir entregar-se aos cuidados do corpo, quando Parténio, o criado de quarto, o fez alterar os planos, com a notícia de que estava ali alguém portador de um assunto qualquer de grande importância e que não podia ser adiado. E assim, mandou embora toda a gente, recolheu-se ao quarto e foi aí assassinado.

Sobre o organização da conjura e do homicídio foi propalado o seguinte. Estavam os conjurados hesitantes sobre o momento e o modo de o atacar - se durante o banho ou durante o jantar -, quando Estéfano, procurador de Domitila e na altura acusado de desvio de dinheiros, lhes ofereceu o seu conselho e ajuda. Andou durante alguns dias com o braço esquerdo envolto em tiras de lã, a pretexto 
de uma lesão, para evitar suspeitas, e, chegado a hora exacta, inseriu ali um chuço. Afirmando que ia revelar uma conspiração, foi por este motivo recebido, e, enquanto o imperador lia estupefacto o bilhete que ele lhe entregara, trespassou-lhe as virilhas. Como o imperador, gravemente ferido, resistia, acometeram-no Clodiano, oficial subalterno, Máximo, liberto de Parténio, Sátur, chefe dos criados de quarto, e um fulano da escola de gladiadores e assassinaram-no com sete golpes.

Um rapaz, que costumava prestar serviço aos Lares do quarto e presenciou o assassínio, contava ainda o seguinte: que, mal Domiciano recebera o primeiro golpe, lhe mandara ir buscar o punhal, que estava escondido debaixo da almofada, e chamar os criados. Mas, à cabeceira da cama, nada encontrou à excepção do cabo e, além disso, deparou com todas as portas fechadas. E o imperador, agarrando e derrubando Estéfano por terra, lutou longo tempo com ele, tentando ora arrebatar-lhe o ferro, ora furar-lhe os olhos com os dedos, apesar de dilacerados.

Foi morto aos catorze dias das Calendas de Outubro, com quarenta e cinco anos de idade, no décimo quinto ano do seu principado. Depois que o cadáver dele foi transportado por uns defunteiros num vulgar esquife, a ama Fílis tratou lhe prestar as honras fúnebres na sua casa de campo, junto à Via Latina, mas depositou os restos mortais no templo da família Flávia e juntou-os às cinzas de Júlia, a filha de Tito, a qual tinha também criado».

\section{COMENTÁRIO}

Pridie quam periret. No trecho transcrito, Suetónio apresenta uma crónica das últimas 24 horas de vida do imperador, marcadas por diversas notações temporais até chegar ao tempus suspecti periculi, referido atrás (14.4). Depois do vago continuis octo mensibus, referido no parágrafo anterior a propósito dos sinais que pressagiavam a morte (15.2), as 
informações são agora cada vez mais precisas: pridie quam periret ...; at circa mediam noctem...; dehinc mane (16.1); horas requirenti pro quinta... sexta ex industria nuntiata est (16.2); sub ipsam horam (17.1).

Sequenti die luna se in aquario cruentaret. Segundo Brind'Amour (1981, 338-344), trata-se de uma releitura posterior da vida e da morte de Domiciano elaborada por uma fonte competente em matéria de astronomia; uma fonte que, segundo aquele autor, se manifesta várias vezes ao longo da Vida e a transforma numa trama astrológica que conduz o imperador ao seu destino. Os dados da astrologia contribuem para enriquecer o enredo e aumentar a tensão, já que o leitor fica a conhecer o fundamento da suspeita que provoca o terror de Domiciano.

Haruspicem ex Germania missum. Segundo Díon Cássio (67.16.2), o arúspice chamava-se Largino Próculo e anunciara que Domiciano iria morrer naquele dia (enquanto Suetónio fala de uma mudança no poder); foi enviado pelo governador para Roma, onde repetiu a predição e foi condenado; mas escapou, porque a sua execução foi adiada para poder ver que o imperador escapara à sua previsão. Terá sido, mais tarde, recompensado por Nerva.

Pro quinta. A hora quinta era mais ou menos entre as 10 e as 11 , se bem que a hora de Verão era mais longa que a de Inverno, uma vez que os Romanos dividiam o dia em 12 horas, entre o nascer e o pôr do sol.

Festinantemque ad corporis curam. Segundo Díon Cássio (67.17.1), Domiciano preparava-se para ir dormir uma sesta.

Parthenius cubiculo praepositus. Parténio era o camareiro, com acesso privilegiado a Domiciano, como bem sabia, por exemplo, Marcial (5.6.2). Enquanto Dión Cássio (67.15.1) e as restantes fontes antigas o apresentam como o mentor da conjura, Suetónio deixa a sua posição na ambiguidade: talvez porque reserva os dados sobre a conjura para o capítulo seguinte e não quer quebrar o suspense que marca esta narrativa. Suetónio sabia bem da sua participação e da morte atroz que sofreu mais tarde às mãos dos pretorianos, castigo consentido por Nerva para acalmar os soldados que reclamavam a cabeça do assassino. Tinha sido altamente honrado 
por Domiciano, que lhe concedera o direito de usar a espada (ius gladii), privilégio extraordinário.

De insidiarum caedisque genere haec fere diuulgata sunt. De modo diferente da focalização que usara por exemplo para a narrativa da morte de César, em que dera previamente ao leitor os pormenores da organização da conjura (Jul. 80.4), no caso de Domiciano, Suetónio atrasa essa informação, o que o obriga a fazer aqui uma analepse para transmitir esses dados. Assim, o biógrafo seguiu até aqui uma narrativa focalizada em Domiciano, fazendo o leitor experimentar de algum modo o terror de saber a hora da morte, mas não saber de onde viria a ameaça. Só agora se começam a nomear progressivamente os implicados e se revela a discussão inicial sobre quando et quo modo; só agora se identifica o até então secreto (qui) mensageiro: Estéfano, procurator de Domitila, sobrinha do imperador e esposa de Flávio Clemente, o referido cônsul cuja execução precipitara a decisão de assassinar o imperador. Segundo Díon Cássio (67.17.1), Estéfano foi escolhido como executor, porque era mais forte que os outros, mas acabou morto pelos que acorreram em auxílio do imperador.

Professusque conspirationis indicium. Na sua Vida de Apolónio, Filóstrato (VA 8.25), Estéfano sustentava que Flávio Clemente havia escapado à morte e se preparava para atacar o imperador.

Vulneribus septem contrucidarunt. o biógrafo nomeia os agressores, evidenciando a proximidade deles em relação ao imperador, referida atrás (14.1) através da menção das suas funções no interior do palácio.

Pugionem puluino subditum... excepto capulo. Segundo Díon Cássio (67.17.1), foi Parténio quem retirou a lâmina do punhal. Só Suetónio menciona uma testemunha ocular: aquele puer que tratava dos Lares do quarto. Mas, ao contrário de Díon e filóstrato, omite qualquer ajuda e faz de Domiciano uma personagem solitária na morte. A solidão em que vive o imperador é acentuada pelas palavras do próprio Domiciano, transmitidas mais tarde (Dom. 21): 'Condicionem principum miserrima' aiebat, 'quibus de coniuratione comperta non crederetur nisi occisis' ("Afirmava que 
era assaz infeliz a condição dos príncipes, pois ninguém acreditava que uma conspiração fora descoberta, a menos que fossem assassinados»).

Occisus est XIIII. Kal. Octb. Tal solidão é acentuada no funeral, ou quase ausência dele. O biógrafo faz notar que foi levado pelos uispillones e na indigna sandapila, o caixão dos pobres. Os últimos cuidados são prestados ao cadáver pela ama, Fílis. Como as amas e a amante, Acte, de Nero (Nero 50), Fúlis mostra verdadeiro apego pelo defunto imperador. O templo dos Flávios, onde Fílis coloca os restos mortais do defunto, é um monumento construído por Vespasiano para servir de mausoléu.

Cineribusque Iuliae Titi filiae. A referência a uma união final com as cinzas de Júlia pode não ser fortuita ou inocente. Parece ganhar significado quando mais à frente (Dom. 22) se diz que foram amantes e que ela morreu na sequência de um aborto forçado por Domiciano. O mais provável é que se trate de uituperatio com base em meros rumores.

Domiciano é apresentado com os topoi retóricos do tirano: cruel, ávido de riquezas e com uma libido desmedida, manifesta por exemplo no abuso de mulheres casadas - e Júlia era casada; além de ser sobrinha, relação considerada incestum ${ }^{7}$ : outro tópico frequentemente associado a tiranos. A morte representa pois o castigo do tirano, depois de viver os seus últimos dias sob uma verdadeira espada de Dâmocles.

O equilíbrio será restabelecido com a referência aos optimi principes que se seguirão a Domiciano. A mensagem final, por oposição aos vícios de Domiciano, e dos tiranos anteriores, será a apologia das virtudes da abstinentia e da moderatio, cultivadas por Nerva, Trajano e Adriano, os nomes implícitos dos imperadores sob os quais o biógrafo faz carreira.

7 Cf., a propósito da união de Cláudio com a sobrinha Agripina, Cl. 26.3: quae ad id tempus incesta habebantur; pelo que precisou de uma autorização especial do senado, alegando interesse do estado. 


\section{BIBLIOGRAFIA}

Brandão, J. L. (2009), Máscaras dos Césares. Teatro e moralidade nas Vidas suetonianas. Coimbra, CECH.

Brind'Amour, P. (1981), "Problèmes astrologiques et astronomiques soulevés par le récit de la mort de Domitien chez Suétone" : Phoenix 35 338-344.

Jones, B. W. (1996), Suetonius. Domitian, ed. with intr., com. and bibl. London, Bristol Classical Press.

Pimentel, M. C. (1993), “A. D. xiv Kal. Oct., hora quinta...”, Boletim de Estudos Clássicos, 20 94-102. 